\title{
Low-cost Shielding to Minimize Radiation Errors of Temperature Sensors in the Field
}

\author{
Julie M. Tarara ${ }^{1}$ \\ USDA-ARS, Horticultural Crops Research Unit, 24106 N. Bunn Road, \\ Prosser, WA 99350
}

Gwen-Alyn Hoheisel

Washington State University Extension, 1121 Dudley Avenue, Prosser, WA 99350

Additional index words. Gill shield, solar, global irradiance, reflectance, albedo, aspiration, thermocouple, relative humidity

\begin{abstract}
The importance of shielding temperature sensors from solar radiation is understood, but there is a lack of prescriptive advice for plant scientists to build inexpensive and effective shields for replicated field experiments. Using the general physical principles that govern radiation shielding, a number of low-cost, passively ventilated radiation shields built in-house was assessed for the measurement of air temperature against the same type of sensor in a meteorological "standard" Gill radiation shield. The base shield material had high albedo $(\approx 0.9)$ and low emissivity (0.03). Aspirated shields were included for simultaneous measurements of temperature and relative humidity. Differences in air temperature $(\Delta T)$ between low-cost shields and the standard Gill were greatest for shields with open bottoms (up to $+7.4^{\circ} \mathrm{C}$ ) and for those with poorly perforated sidewalls. Open-bottomed shields were prone to heating from reflected radiation. Tube-shaped shields appeared to require more than $30 \%$ sidewall perforation for convection by ambient wind (up to $4 \mathrm{~m} \cdot \mathrm{s}^{-1}$ ) to offset the midday radiation load of the shield. The smallest daytime $\Delta \mathrm{T}$ were between aspirated shields and the standard Gill, averaging less than $\pm 0.5{ }^{\circ} \mathrm{C}$. Among passively ventilated shields, the smallest daytime $\Delta \mathrm{T}$ consistently were produced by a shield that emulated the stacked plate design of the standard Gill for a total of U.S. \$4.00 in materials and 45 min construction time. Eighty-nine percent of all daytime $\Delta \mathrm{T}$ for the "homemade Gill" shield was $1.5^{\circ} \mathrm{C}$ or less. The combination of low ambient wind speed (less than $1 \mathrm{~m} \cdot \mathrm{s}^{-1}$ ) and high global irradiance (greater than $600 \mathrm{~W} \cdot \mathrm{m}^{-2}$ ) produced the largest $\Delta \mathrm{T}$ for all passively ventilated shields, the magnitude of which varied with shield design; stacked plate configurations were more effective shields than were tube-based configurations. Nighttime $\Delta \mathrm{T}$ were inconsequential for all shields. Cost-effective radiation shielding can be achieved by selecting shield materials and a configuration that minimize daytime radiation loading on the shield while maximizing the potential for convective transfer of that radiation load away from the shield and the sensor it houses.
\end{abstract}

For automated weather stations, recommendations and minimum standards exist for proper shielding of temperature sensors to minimize errors that arise from solar radiation striking the sensor (ASAE, 2004; Hubbard et al., 2001; WMO, 2006). Although cost is a consideration for weather stations, it does not supersede the importance of sensor selection and an attempt at standardization

Received for publication 6 Dec. 2007. Accepted for publication 18 Mar. 2007

We thank John Ferguson and Patrick Humberstad for technical support and Carolyn Scagel for helpful editorial comments.

Mention of a trademark, proprietary product, or vendor does not constitute a guarantee or warranty of the product by the U.S. Department of Agriculture and does not imply its approval to the exclusion of other products or vendors that also may be suitable.

${ }^{1}$ To whom reprint requests should be addressed; e-mail jtarara@wsu.edu
1979; Lin et al., 2001a) and its ventilation (Gill, 1979, 1983; Lin et al., 2001a, 2001b), because two forms of heat transfer, radiation and convection, generally govern shield design. Because solar radiation causes the largest errors in air temperature measurements (Fuchs and Tanner, 1965; Gill, 1979; Hubbard et al., 2001), materials for radiation shields tend to be chosen first for optical properties that minimize daytime errors: high solar reflectance and low emissivity (thermal emittance). Where nighttime errors specifically are of concern (e.g., studies of nocturnal insect behavior), shield material with high emissivity is preferred (Lin et al., 2001a).

The flat plate and the tube are the two basic shapes that describe most radiation shields. One shield that has been adopted widely in weather station networks is a stacked plate design known as the "Gill" shield, after its developer (Gill, 1979, 1983). Shield ventilation is achieved by one of two fundamental approaches: passive, or natural ventilation, and forced ventilation. Passive ventilation relies on ambient wind to transfer heat away from the shield and the sensor. Passively ventilated shields often suffice for measurements of air temperature alone, particularly for sensors of small thermal mass (e.g., thermocouples, thermistors). Forced ventilation, more commonly referred to as aspiration, uses a powered fan to draw air across the sensor at a rate high enough to offset radiation-induced heating within the shield. Aspirated shields often are required for concurrent measurements of temperature and relative humidity [(RH); e.g., Fritschen and Gay, 1979; WMO, 2006], for measuring temperature near the ground, or for measurements in confined spaces where the sensor may be decoupled from the air that is to be measured. Although it generally is accepted that the greatest measurement accuracy is achieved from aspirated sensors (e.g., WMO, 2006), the major drawback of aspirated shields is that they require a power source.

Using fundamental principles of shield design from the environmental biophysics and meteorological literature (e.g., Fritschen and Gay, 1979; Fuchs and Tanner, 1965; Gill, 1979, 1983; Lin et al., 2001a), the objective of this research was to demonstrate these principles for the horticultural scientist using several designs of inexpensive and easily constructed radiation shields for two types of temperature sensors that are commonly deployed in field experiments: 1) the thermocouple, a cheap, easy-to-use sensor of small thermal mass; and 2) a combined temperatureRH sensor with moderate thermal mass. Passively ventilated designs were intended to cost less than U.S. \$5.00 in materials and require less than $1 \mathrm{~h}$ to construct. Shield "success" was defined as shielded sensors consistently producing daytime air temperature values that were within $\approx 1{ }^{\circ} \mathrm{C}$ of those from identical sensors in "standard" passively ventilated Gill shields. Shieldedaspirated sensors were compared with those in standard Gill shields to provide information to scientists who are able to deploy 
powered systems and who choose a forced ventilation approach, particularly for simultaneous measurements of temperature and $\mathrm{RH}$.

\section{Materials and Methods}

The experiment was conducted near Prosser, WA (lat. $46^{\circ} 18^{\prime} \mathrm{N}$, long. $119^{\circ}$ $\left.45^{\prime} \mathrm{W}\right)$. All temperature and temperatureRH sensors were mounted $2 \mathrm{~m}$ above a bare, dry soil surface, the average midday albedo of which was 0.21 , within the range that one would expect for a soil of low organic matter (Campbell and Norman, 1998; Monteith and Unsworth, 1990). Sensors were installed in a grid with a separation distance of $2 \mathrm{~m}$. Each type of radiation shield was replicated three times in a completely randomized design. The nearest building structure was $\approx 30 \mathrm{~m}$ to the north of the sensor arrays. There were no structures or trees within tens of meters to the south and west of the experiment. The nearest irrigated surface (lawn) was $\approx 40 \mathrm{~m}$ west of the plot. Prevailing winds were south to southwest.

Air temperature measured independently of RH was by type T thermocouple (copperconstantan; 0.5-mm diameter; part no. PRT-24-SLE; Omega Engineering, Stamford, $\mathrm{CT}$ ). All thermocouple junctions (2-mm long) were manufactured in-house. Several centimeters $(\approx 12$ to 18$)$ of thermocouple lead wire were coiled inside the shields to minimize errors associated with conduction of heat along the lead to the thermocouple junction. Combined temperature-RH sensors were manufactured by Vaisala (model HMP45C; Campbell Scientific, Logan, UT). A passively ventilated Gill shield (model 41002; R.M. Young, Traverse City, MI) was used as the standard of comparison for both the thermocouples and the temperatureRH sensors. Wind speed and direction were measured by a three-cup anemometer and wind vane (Wind Sentinel; Met One, Grants Pass, OR). Global irradiance $\left(\mathrm{R}_{\mathrm{s}}\right)$ was measured by a pyranometer (model 8-48; Eppley Laboratories, Newport, RI). Sensor signals were scanned at 5-s intervals and averaged every 15 min by datalogger (CR-10X; Campbell Scientific). A solid-state thermocouple multiplexer (AM-25T; Campbell Scientific) was used to switch among thermocouple signals. The data acquisition system was housed in an insulated ice chest that was placed in a nearby travel trailer to minimize thermal gradients across the measurement panel. A control for signal error attributable to any thermal gradients across the panel was provided by several thermocouples wired into input channels across the measurement panel with their junctions buried $\approx 0.6 \mathrm{~m}$ below the bare ground surface. Measurements from these thermocouples agreed to within $\pm 0.15^{\circ} \mathrm{C}$.

An 8-mm thick "foil bubble wrap" or "foil bubble insulation" (polyethylene bubblepack aluminum foil-faced insulation; Reflectix, Markleville, IN) that can be obtained at any hardware outlet was used to construct several designs of passively ventilated radiation shield. The material's surface emissivity $(0.03)$ was determined by the manufacturer according to ASTM Standard C1371 (ASTM International, West Conshohocken, PA). Because the surface is highly specular rather than a diffuse reflector, spectrometer estimates (Fieldspec-Full Range; Analytical Spectral Devices, Boulder, CO) of its albedo (shortwave reflectance) were suspect, so we estimated the albedo of the foil surface in the field using a pair of inverted pyranometers (Eppley model $8-48 ; 0.285$ to $2.8 \mu \mathrm{m}$ ) that had been recalibrated by the manufacturer differing in output by $0.4 \%\left(\approx 3 \mathrm{~W} \cdot \mathrm{m}^{-2}\right)$ under irradiance greater than $700 \mathrm{~W} \cdot \mathrm{m}^{-2}$. Albedo was estimated as the ratio between reflected and incident irradiance for measurements recorded between 1100 and $1300 \mathrm{HR}$ (local standard time) under overcast skies to minimize errors resulting from specular reflectance. The approximate albedo of the reflective surface was 0.88 . If painted flat white, the bubble wrap surface had an average albedo of 0.72 .

In-house-constructed radiation shields represented simple to complex variations of the basic shield shapes of plates and tubes (Figs. 1-3; Table 1). All passively ventilated shields were constructed from the same base material (i.e., reflective foil insulation) so that designs could be used to demonstrate advantages and disadvantages of various physical configurations. Among passively ventilated shields, the "cone" represents the simplest plate configuration; the "double cone" is the simplest possible stacked plate (Fig. 1). The "hanging tube" (Fig. 2) represents a simple vertically oriented tube shield with a $1: 3$ diameter:height ratio. Its solid sidewalls could be expected to demonstrate a "chimney"
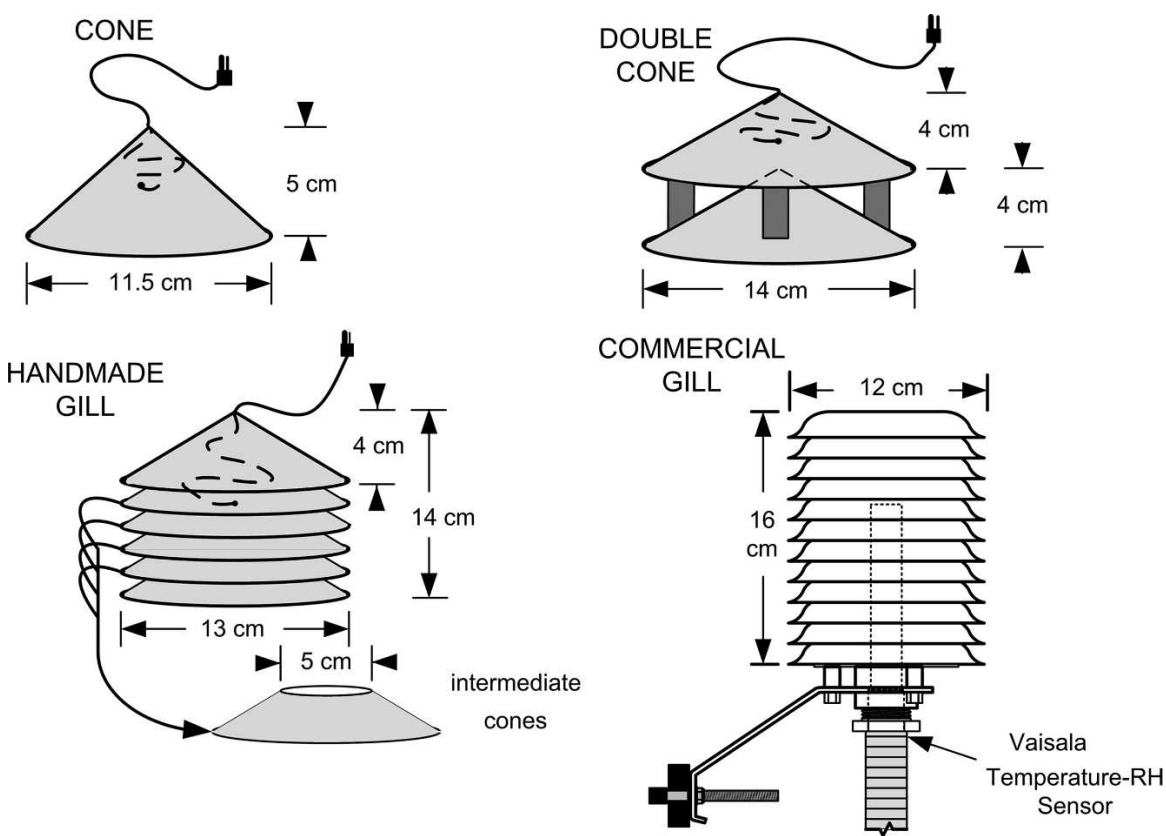

Fig. 1. Schematic diagrams of plate-shaped, passively ventilated radiation shields. The commercial Gill shield housed both a thermocouple and a temperature-relative humidity sensor. All in-house built shields housed a thermocouple, the location of which is denoted by the dashed line (lead wire) and black dot (junction). effect for rising warm air. The "rocket" and cally oriented tube with top or bottom plates. The pagoda relies on natural ventilation from the bottom of the shield and from perforations that comprise $\approx 10 \%$ of the sidewall surface. Because of the closed-bottom approach to the rocket, perforation was near the top and bottom of the tube, representing $\approx 30 \%$ of sidewall surface area. The "handmade Gill" included six plates spaced slightly farther apart than the plates on the commercial Gill for ease of construction (Fig. 1). The length of the handmade Gill was twothirds that of the commercial shield because the in-house version did not need to accommodate a sensor package as long as the Vaisala temperature- $\mathrm{RH}$ probe. Since the experiment was conducted, the 12-plate commercial Gill has been supplanted by the manufacturer with a 10-plate version (model 41003; R.M. Young).

The approximate time required to construct a given shield was recorded only after the first shield of the finalized design was assembled. The same individual constructed all shields. Estimates of materials cost for each shield were all-inclusive except for the cost of the subminiature thermocouple connector, which is independent of shield design. The complete set of materials used for passively ventilated shields was foil bubble wrap, hot-melt glue, rigid foam board, cable ties, and foil tape.

Aspirated shields (Fig. 3) incorporated thin-walled polyvinyl chloride (PVC) pipe and DC-powered brushless fans and were designed to support a thermocouple or a temperature-RH sensor with supplemental thermocouple. The PVC cylinder was the "pagoda" are hybrid designs of a verti- 

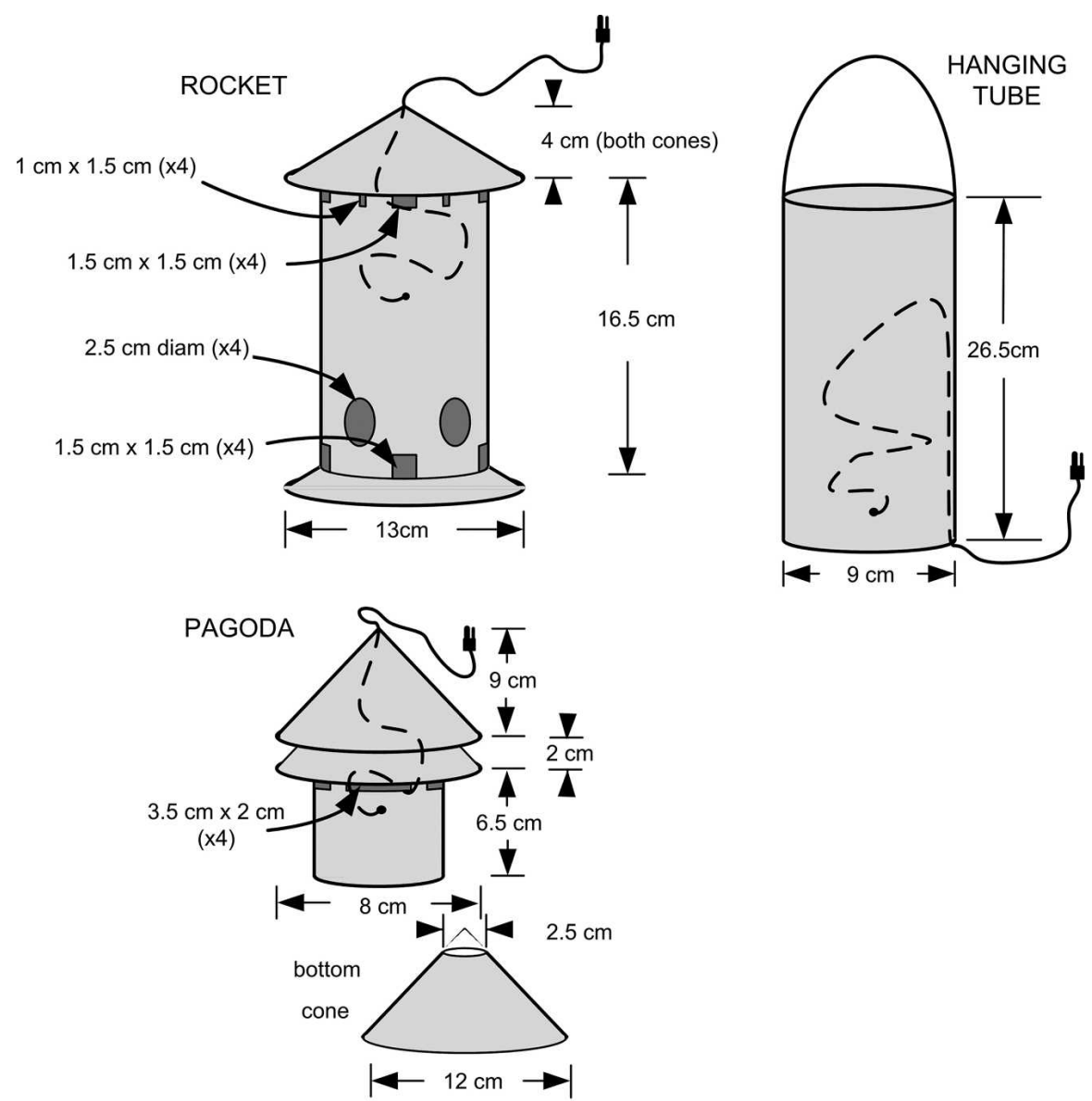

Fig. 2. Schematic diagrams of tube-shaped, passively ventilated radiation shields. The "pagoda" shield had $\approx 10 \%$ sidewall perforation and the "rocket" had $\approx 30 \%$ sidewall perforation. All in-house built shields housed a thermocouple, the location of which is denoted by the dashed line (lead wire) and black dot (junction).
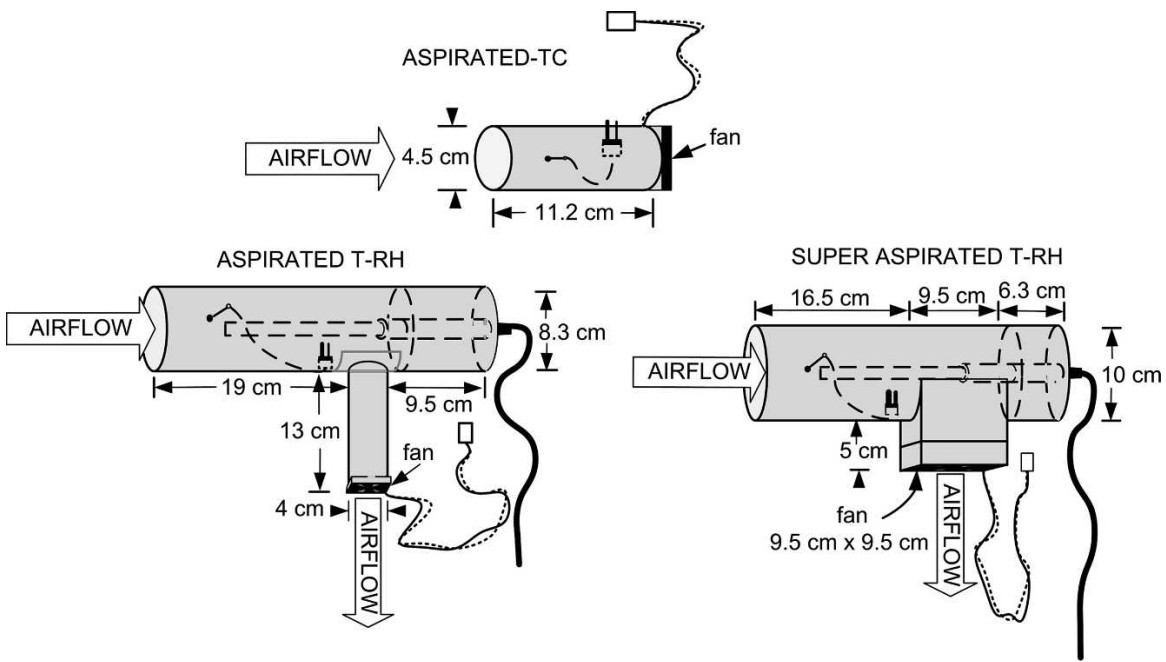

Fig. 3. Schematic diagrams of aspirated radiation shields. Aspirated thermocouple is the aspirated shield for a single thermocouple. Aspirated temperature-relative humidity (T-RH) is the low-velocity $(1.2$ $\left.\mathrm{m} \cdot \mathrm{s}^{-1}\right)$ aspirated shield for a T-RH sensor; superaspirated T-RH is the high-velocity $\left(4.4 \mathrm{~m} \cdot \mathrm{s}^{-1}\right)$ aspirated shield for a T-RH sensor. The dashed outline depicts the position of the T-RH sensor along the central axis of the tube. Aspirated T-RH and superaspirated T-RH shields also included a thermocouple, the location of which is indicated by a single dashed line (lead wire) and black dot (junction) wrapped externally with the foil bubble wrap material before deployment to the field. The temperature-RH sensor was mounted horizontally within the shield midway between top and bottom of the tube. Shields were oriented with the air intake pointed north to avoid direct beam radiation striking the sensor. Three models of $12-\mathrm{V}$ DC fans were used to match air flow rates with shield size and sensor type (low or moderate thermal mass). The thermocouple ("aspirated TC") was aspirated at a mean air speed of $1.8 \mathrm{~m} \cdot \mathrm{s}^{-1}$ (0.09-A fan, model JF0413SIM; Jameco Electronics, Belmont, CA). The low-speed temperature-RH shield ("aspirated T-RH") was aspirated at a mean air speed of $1.2 \mathrm{~m} \cdot \mathrm{s}^{-1}$ (0.09-A fan, SUNON model KD1204KBX-8; Jameco Electronics). The high-speed ("superaspirated T-RH”) temperature-RH shield was aspirated at a mean air speed of $4.4 \mathrm{~m} \cdot \mathrm{s}^{-1}$ (0.28-A fan, NMB model 3610KL-04W-B40; Jameco Electronics). Air speed at the entrance of the tube was measured by hot-wire anemometer (model TA-5; Airflow Technical Products, Netcong, NJ).

Because of input channel limitations, three replicates of eight sensor-shield combinations could be assessed simultaneously. Therefore, short-duration ( 2 to $4 \mathrm{~d}$ ) daytime tests were conducted to narrow the range of shields to eight for inclusion in an 11-d run that covered all periods of the day beginning on day of year 235, 2005. Aspirated TC and three passively ventilated shields with side walls (Fig. 2) were included in the short tests during midday hours (periods 3 to 5). Data for all other shields were acquired during the 11-d run. Each day was divided into seven periods relevant to the diurnal cycle of solar radiation (Fig. 4). Days with rain or overcast skies were eliminated from the analysis.

A difference in air temperature $(\Delta \mathrm{T})$ is defined as that between the given sensor type (thermocouple or temperature-RH sensor) in an experimental radiation shield and the air temperature measured by the same sensor type in a commercial Gill shield. Positive values of $\Delta \mathrm{T}$ indicate that air temperature in the experimental shield was higher than that in the commercial Gill shield; conversely, negative values of $\Delta \mathrm{T}$ indicate that air temperature in the experimental shield was lower than that in the commercial Gill shield. Differences between the in-house-built shields and the commercial Gill, as well as differences between the two sensors within the commercial Gill, were analyzed with a mixed model (Proc Mixed). A repeated statement was used to account for the autocorrelation in timeseries data and least squared means were adjusted by Bonferroni (SAS Version 9.1; SAS Institute, Cary, NC). Significant effects of solar radiation, wind speed, and their interaction were tested with a general linear model (Proc GLM). Mean values across three replicates are reported throughout.

\section{Results}

Within the commercial Gill shield, the thermocouple and temperature- $\mathrm{RH}$ sensor 
Table 1. Shape, geometric dimensions, approximate construction time, materials cost, and shield material of 10 radiation shields included in the experiment sorted by class of ventilation.

\begin{tabular}{|c|c|c|c|c|c|}
\hline Ventilation class/type & Base shape & $\begin{array}{c}\text { Dimensions } \\
(\mathrm{ht} . \times \text { diam. })(\mathrm{cm})\end{array}$ & $\begin{array}{l}\text { Construction } \\
\text { time (min) }\end{array}$ & $\begin{array}{l}\text { Materials } \\
\text { cost (\$U.S.) }\end{array}$ & Primary materials \\
\hline Cone & Single plate & $5 \times 11.5$ & 10 & 0.70 & Reflective foil \\
\hline Double cone & Stacked plates & $8 \times 14$ & 20 & 2.00 & Reflective foil, foam spacers \\
\hline Commercial Gill & Stacked plates & $16 \times 12$ & NA & $180.00^{z}$ & White thermoplastic \\
\hline Pagoda & Tube (vertical), top-stacked plates & $17.5 \times 12$ & 30 & 2.00 & Reflective foil, foam spacers \\
\hline Rocket & Tube (vertical), top- and bottom-stacked plates & $20.5 \times 13$ & 30 & 2.50 & Reflective foil \\
\hline $\mathrm{TC}^{\mathrm{y}}$ & Tube (horizontal) & $11.2 \times 4.5$ & 45 & 12.00 & PVC pipe, reflective foil, fan \\
\hline $\mathrm{T}-\mathrm{RH}^{\mathrm{x}}$ & Tube (horizontal) & $32.5 \times 8.3$ & 120 & 21.00 & PVC pipe, reflective foil, fan \\
\hline Super $\mathrm{T}-\mathrm{RH}^{\mathrm{x}}$ & Tube (horizontal) & $32.3 \times 10$ & 120 & 26.00 & PVC pipe, reflective foil, fan \\
\hline
\end{tabular}

${ }^{\mathrm{z}}$ Retail price.

${ }^{\mathrm{y}} \mathrm{TC}=$ thermocouple.

${ }^{\mathrm{x}} \mathrm{T}-\mathrm{RH}=$ temperature-relative humidity sensor.

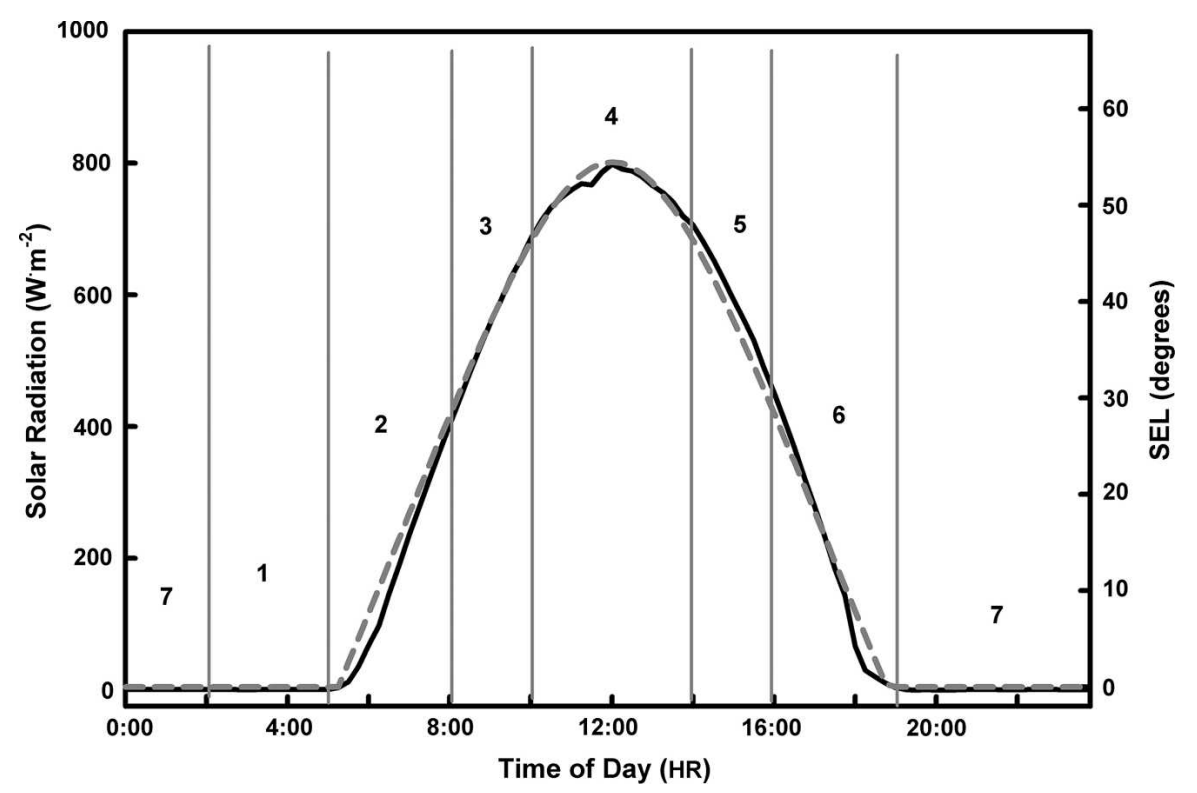

Fig. 4. Exemplary diurnal curve of global irradiance $\left(\mathrm{R}_{\mathrm{s}}\right.$; solid line) and solar elevation angle (SEL; dashed line) with the seven periods into which each $24 \mathrm{~h}$ was divided for analysis of air temperature measurements. Data were recorded on day of year 236, 2005.

did not significantly differ from each other and agreed on average $(\mathrm{n}=2112,15-\mathrm{min}$ averages) to within $0.04{ }^{\circ} \mathrm{C}$, well within the accuracy of a Type $\mathrm{T}$ thermocouple, with a maximum divergence of $\pm 0.8{ }^{\circ} \mathrm{C}$. Among passively ventilated shields, significant differences in air temperature between the inhouse shields and the commercial Gill were apparent only during the day (periods 2 to 5) with almost no significant differences at night (Figs. 5 and 6). For the simplest plate design, the cone, $\Delta \mathrm{T}$ across the data set $(\mathrm{n}=2112)$, ranged between -1.2 and $+5.4{ }^{\circ} \mathrm{C}$. Of all observed $\Delta \mathrm{T}$ for the cone, $63 \%$ were $1.5^{\circ} \mathrm{C}$ or less, but only $37 \%$ of daytime $\Delta \mathrm{T}$ (periods 2 to 6 ) and $5 \%$ of midday $\Delta \mathrm{T}$ (periods 3 to 5 ) fell below this value. The $\Delta \mathrm{T}$ was affected significantly by wind speed $(P<0.030), \mathrm{R}_{\mathrm{s}}$ $(P<0.0001)$, and the interaction between the two driving forces $(P<0.0001)$, increasing linearly with $\mathrm{R}_{\mathrm{s}}$ (Fig. 7A). However, $\Delta \mathrm{T}$ increased with wind speed up to $\approx 1 \mathrm{~m} \cdot \mathrm{s}^{-1}$ and then declined (Fig. 7A). The simplest stacked plate design, the double cone, had a range of $\Delta \mathrm{T}$ across the data set $(\mathrm{n}=2112)$ between -1.2 and $+2.6{ }^{\circ} \mathrm{C}$ with $46 \%$ of daytime $\Delta \mathrm{T}$ (periods 2 to 6 ) and $23 \%$ of midday $\Delta \mathrm{T}$ (periods 3 to 5 ) $1.5^{\circ} \mathrm{C}$ or less. The $\Delta \mathrm{T}$ of the double cone was significantly affected by wind speed $(P<0.0001), \mathrm{R}_{\mathrm{s}}$ $(P<0.0001)$, and the interaction between the two $(P<0.0001)$. The presence of a shielded bottom in the double cone was evident in a logarithmic response of $\Delta \mathrm{T}$ to $\mathrm{R}_{\mathrm{s}}$, with an asymptote above $\approx 200 \mathrm{~W} \cdot \mathrm{m}^{-2}$, in contrast to $\Delta \mathrm{T}$ in the open-bottomed cone, with its linear response to $R_{s}$ across the entire range of values during the study ( 0 to $\approx 850$ $\mathrm{W} \cdot \mathrm{m}^{-2}$ ). Because data were retained only for days with predominantly clear skies, $\mathrm{R}_{\mathrm{S}}$ was less than $200 \mathrm{~W} \cdot \mathrm{m}^{-2}$ only early and late in the day at solar elevation angles $15^{\circ}$ or less.

Air temperature in the handmade Gill shield consistently was higher than that in the commercial Gill only between $\approx 800$ and $1400 \mathrm{HR}$ (Figs. 5 and 6), a period that is critical to many biological studies. Over $11 \mathrm{~d}$, $\Delta \mathrm{T}$ was $1.5^{\circ} \mathrm{C}$ or less for $89 \%$ of daytime (periods 2 to 6 ) and $87 \%$ midday (periods 3 to 5) measurements. Across the entire dataset for the handmade Gill $(\mathrm{n}=2112), \Delta \mathrm{T}$ was between -0.7 and $+2.2{ }^{\circ} \mathrm{C}$; $93 \%$ of all observed $\Delta \mathrm{T}$ were $1.5{ }^{\circ} \mathrm{C}$ or less and twothirds of all $\Delta \mathrm{T}$ were $1.0^{\circ} \mathrm{C}$ or less. The $\Delta \mathrm{T}$ of the handmade Gill was affected significantly by wind $(P<0.0001), \mathrm{R}_{\mathrm{s}}(P<0.0001)$, and the interaction between the two $(P<0.0001)$. Like with the double cone, $\Delta \mathrm{T}$ of the homemade Gill had a logarithmic response to $R_{s}$ approaching an asymptote of $\approx 200 \mathrm{~W} \cdot \mathrm{m}^{-2}$. Again, this corresponded to early morning and evening, or solar elevation angles $15^{\circ}$ or less. The largest $\Delta \mathrm{T}$ occurred at wind speeds $\approx 1 \mathrm{~m} \cdot \mathrm{s}^{-1}$ regardless of $\mathrm{R}_{\mathrm{s}}$. The response surface of the homemade Gill shield (Fig. 7B) closely resembled that of the cone (Fig. 7A), but with smaller $\Delta \mathrm{T}$.

Passively ventilated shields with side walls (Fig. 2) produced the largest midday $\Delta \mathrm{T}$ (periods 3 to 5) among all in-house-built shields with average performance in the general increasing order: hanging tube < pagoda $<$ rocket. Across daytime data $(\mathrm{n}=$ 82), air temperatures in all three tube-based shields were higher than those in the commercial Gill, with $\Delta \mathrm{T}$ ranges of +1.4 to $+3.4{ }^{\circ} \mathrm{C}$ for the rocket, +2.4 to $+7.2{ }^{\circ} \mathrm{C}$ for the pagoda, and +2.0 to $+7.4{ }^{\circ} \mathrm{C}$ for the hanging tube. The $\Delta \mathrm{T}$ of the hanging tube was affected significantly only by solar radiation $(P<0.001)$, whereas convective heat transfer apparently was ineffective $(P<0.395$ for wind speed). For example, at ambient wind speeds between 2.5 and $3 \mathrm{~m} \cdot \mathrm{s}^{-1}, \Delta \mathrm{T}$ was between +4 and $+5{ }^{\circ} \mathrm{C}$. By contrast, at ambient wind speeds above $1.5 \mathrm{~m} \cdot \mathrm{s}^{-1}, \Delta \mathrm{T}$ for the rocket generally was below $+2{ }^{\circ} \mathrm{C}$. Nonetheless, at low ambient wind speed and high solar radiation, midday $\Delta \mathrm{T}$ for the rocket consistently was greater than $2.5^{\circ} \mathrm{C}$, indicating that $\approx 30 \%$ sidewall ventilation in this combination tube-and-plate design was less effective than a stacked plate configuration. Under similar conditions, $\Delta \mathrm{T}$ of the homemade Gill never exceeded $+1.8^{\circ} \mathrm{C}$. The $\Delta \mathrm{T}$ for the rocket was affected significantly by $\mathrm{R}_{\mathrm{s}}(P<0.001)$ and the interaction between 


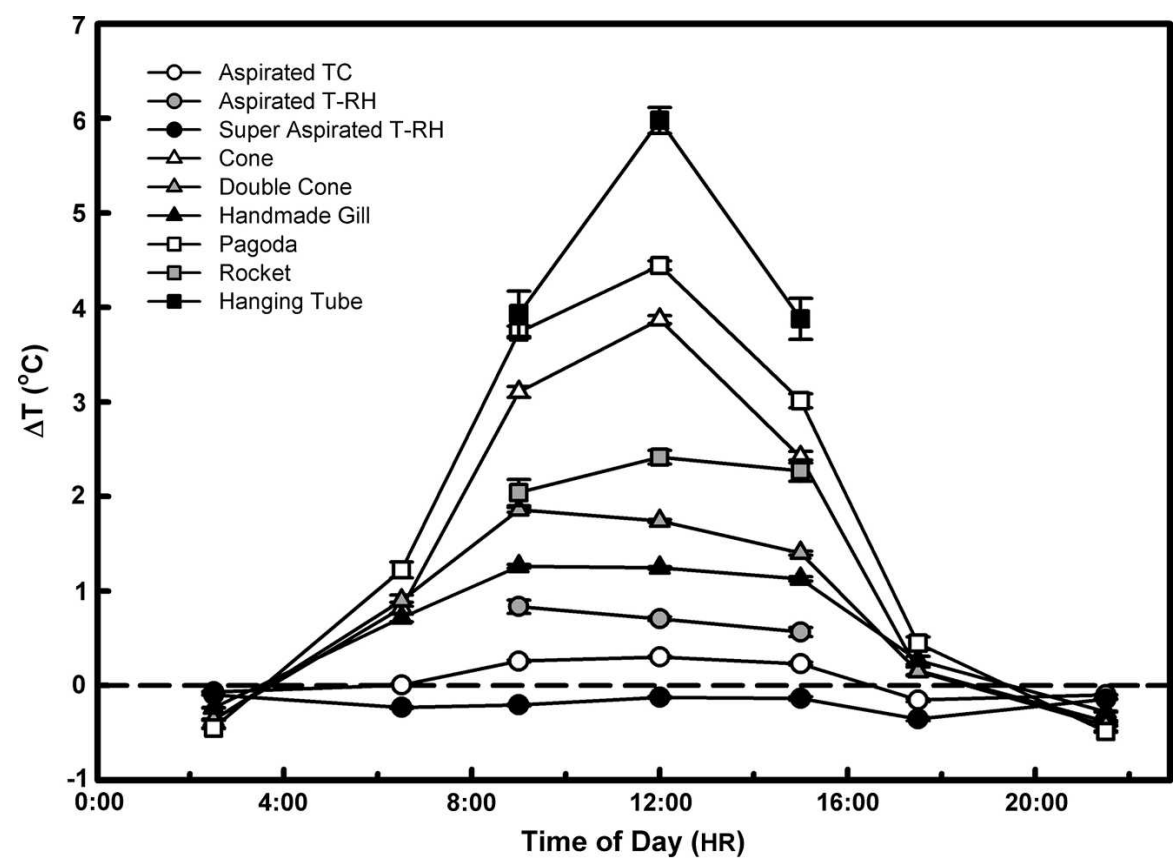

Fig. 5. Mean difference in measured air temperature $(\Delta \mathrm{T})$ between sensors in an experimental radiation shield and the same type of sensor in a standard commercial Gill shield for each of seven periods into which the day was divided. Symbols are plotted at the midpoint of the period (HR). Error bars represent \pm 1 SE.

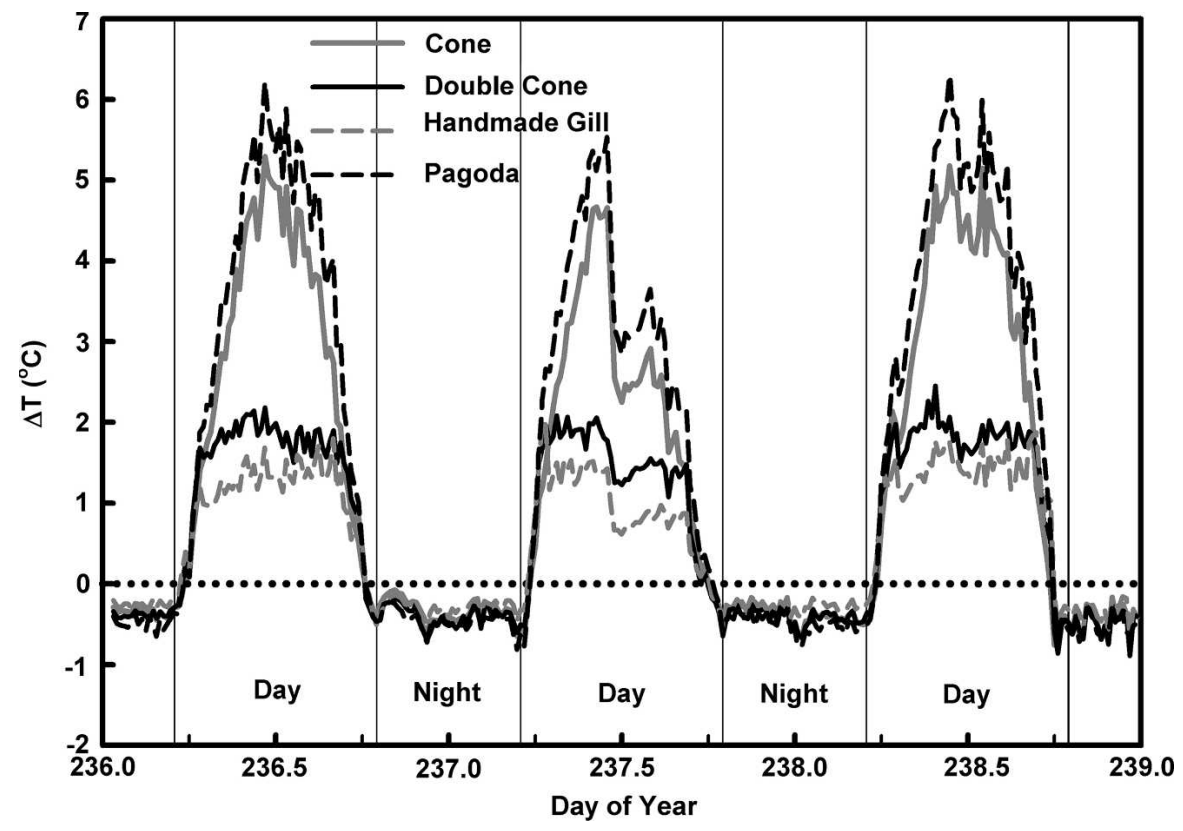

Fig. 6. Difference in measured air temperature $(\Delta \mathrm{T})$ between sensors in a passively ventilated experimental radiation shield and the same type of sensor in a standard commercial Gill shield over three exemplary days with clear skies and maximum global irradiance of 800 to $830 \mathrm{~W} \cdot \mathrm{m}^{-2}$. Vertical lines demarcate day (periods 2 to 6 ) and night (periods 1,7 ).

$\mathrm{R}_{\mathrm{s}}$ and wind speed $(P<0.0005)$. The $\Delta \mathrm{T}$ of the pagoda was not significantly affected by wind speed ( 0 to $\left.3.0 \mathrm{~m} \cdot \mathrm{s}^{-1}\right)$, but it was significantly affected by $\mathrm{R}_{\mathrm{s}}(P<0.0001)$ and the interaction between $\mathrm{R}_{\mathrm{s}}$ and wind $(P<0.0001)$. Only $16 \%$ of midday values (periods 3 to 5 ) for the pagoda fell below $+1.5^{\circ} \mathrm{C}$. Common to all passively ventilated shields, the largest $\Delta \mathrm{T}$ occurred at low wind
Among aspirated sensors, aspirated TC was not significantly different from the thermocouple in the commercial Gill shield at any period of the day with a range in $\Delta \mathrm{T}$ ( $\mathrm{n}=$ 2112) between -1.3 and $+0.8{ }^{\circ} \mathrm{C}$ (Figs. 5 and 8). Of all observed $\Delta \mathrm{T}$ for aspirated $\mathrm{TC}, 95 \%$ were $0.5{ }^{\circ} \mathrm{C}$ or less, as were $86 \%$ of midday values (periods 3 to 5). Air temperature in the aspirated TC shield tended to be slightly lower than that in the commercial Gill during the evening and at night (Fig. 8) when ambient wind speeds generally were at their lowest and the Gill was least effectively ventilated. There was a significant interaction $(P<0.0001)$ between wind speed and $\mathrm{R}_{\mathrm{s}}$ on $\Delta \mathrm{T}$, apparent at wind speeds above $\approx 3 \mathrm{~m} \cdot \mathrm{s}^{-1}$ and $\mathrm{R}_{\mathrm{s}}$ greater than $600 \mathrm{~W} \cdot \mathrm{m}^{-2}$ when air temperatures in the aspirated TC shield consistently were higher than those in the commercial Gill (Fig. 9A). Higher ambient wind speeds apparently offset a greater fraction of the total radiation load of the commercial Gill shield than could be dissipated by the fixed air speed of the aspirated TC shield. Air temperature in the low speed aspirated T-RH shield (Fig. 5) tended to be higher than that in commercial Gill, although not always significantly so $(\mathrm{n}=98)$, with a minimum $\Delta \mathrm{T}$ of $+0.05{ }^{\circ} \mathrm{C}$ and a maximum $\Delta \mathrm{T}$ of $+1.5^{\circ} \mathrm{C}$ during the middle of the day (periods 3 to 5 ) for global irradiance values up to $\approx 900$ $\mathrm{W} \cdot \mathrm{m}^{-2}$. Wind speeds were in a fairly narrow range $\left(0.7\right.$ to $\left.3.0 \mathrm{~m} \cdot \mathrm{s}^{-1}\right)$ during the shortduration tests of the low-speed aspirated T-RH shield. Air temperature in the superaspirated T-RH shield (Figs. 5 and 8) was rarely significantly different from that in the commercial Gill with a range of $\Delta \mathrm{T}(\mathrm{n}=$ 2112) between -1.6 and $+1.24{ }^{\circ} \mathrm{C}$. Solar radiation and wind speed, as well as their interaction, significantly affected $\Delta \mathrm{T}(P<$ 0.0001 ; Fig. 9B). Air temperature in the superaspirated T-RH shield tended to be less than that in the commercial Gill at low wind speed and low $\mathrm{R}_{\mathrm{s}}$ but slightly higher than that in the commercial Gill at higher $\mathrm{R}_{\mathrm{s}}$ when ambient wind speed also was high enough to ventilate the Gill shield effectively.

\section{Discussion}

There is a legitimate need among field biologists, including horticulturists, for inexpensive and effective radiation shields because of the large number of sensors that may be deployed in a replicated field experiment. The commercial Gill shield made of injected thermoplastic is appropriate for weather stations and for a reference meteorological mast in an experiment, but at a cost of U.S. $\$ 180$, it is too expensive for many horticulturists, agronomists, ecologists, and others to consider for replicated plots. Stacked plate shields exist for some selflogging temperature and T-RH sensors (e.g., Watchdog, Spectrum Technologies, Plainfield, IL; Hobo, Onset, Pocasset, MA) at approximately one-third the price of a standard Gill shield. Other authors have investigated inexpensive shields for deployment around livestock shelters, where commercial 

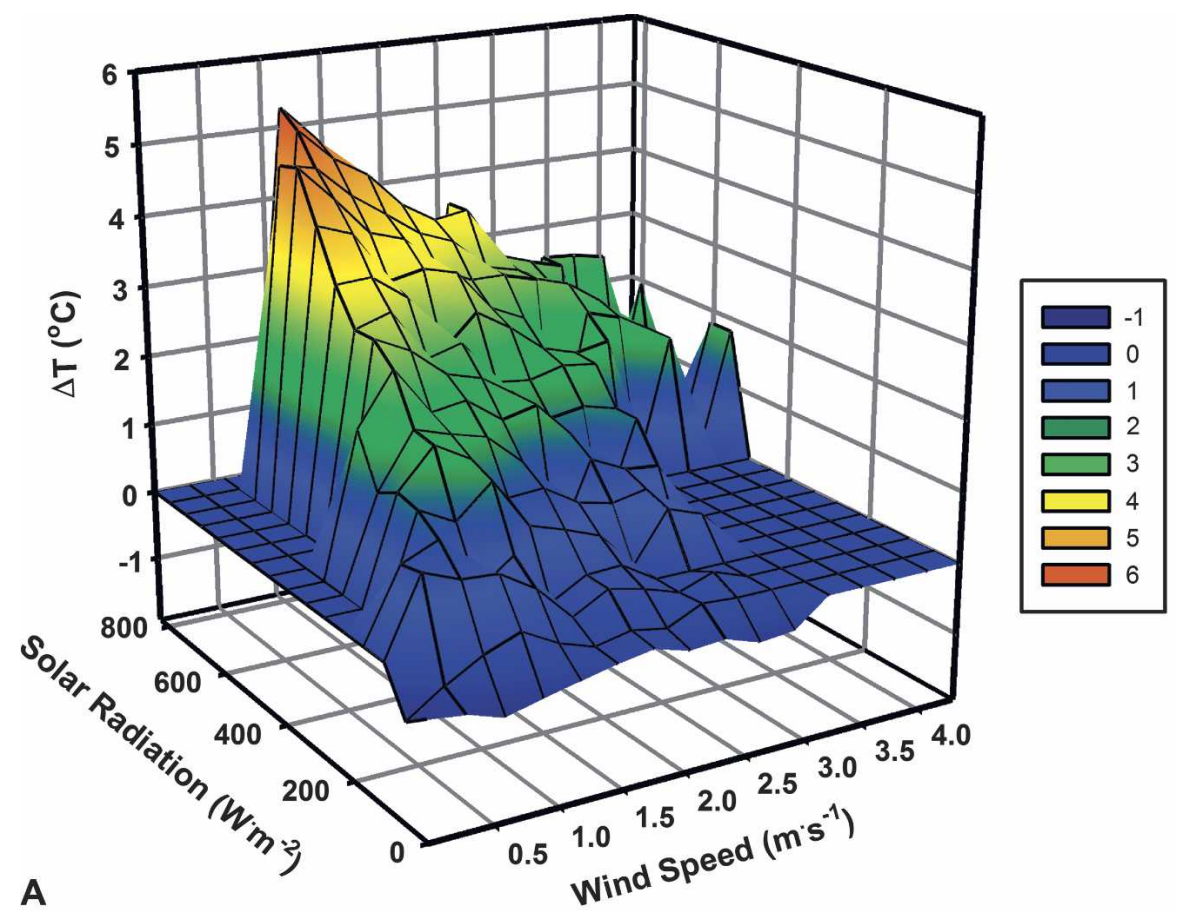

A

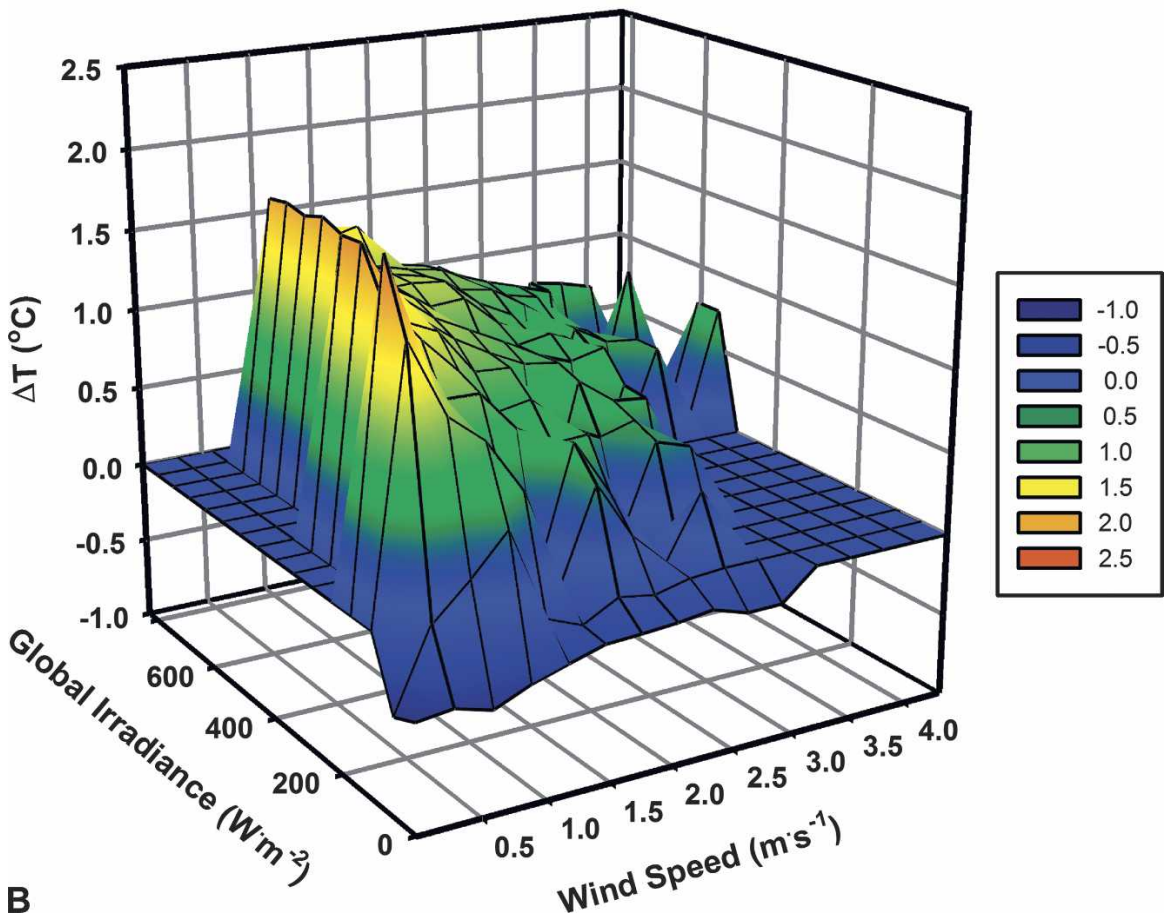

Fig. 7. Response surface of the difference in measured air temperature $(\Delta \mathrm{T})$ between sensors in an experimental radiation shield and the same type of sensor in a standard commercial Gill shield against the two main driving forces of $\Delta \mathrm{T}$, solar radiation [global irradiance $\left(\mathrm{R}_{\mathrm{s}}\right)$ ] and wind speed. (A) Cone shield, the simplest plate configuration, with an open bottom. (B) Handmade Gill shield, a low-cost mockup of a standard commercial Gill shield.

Gill shields are too fragile to withstand curious animals (Wheeler et al., 2002). Requirements for robustness in horticultural field experiments generally are less stringent, so more attention can be paid to finding highly reflective, inexpensive materials and to designing the shield to best meet established physical principles.

There are many common materials from which radiation shields may be constructed. Strictly in terms of optical properties, the following surface coatings were recommended in order of preference: aluminized Mylar (DuPont, Wilmington, DE), flat white paint, and clear plastic coatings on the upper surface of polished aluminum foil (Fuchs and Tanner, 1965). The "foil bubble insulation" used in the present study could be desirable because of its optical and thermal properties and low cost $(\approx$ U.S. $\$ 5.50$ per $\left.\mathrm{m}^{2}\right)$. The surface has high shortwave reflectance $(\approx 0.9)$ and low emissivity $(0.03)$, advantageous for minimizing daytime errors in the measurement of air temperature. The low emissivity of the material minimizes longwave radiation transfer from the inner surface of the shield to the sensor. It has been suggested that a difference in temperature of $+5^{\circ} \mathrm{C}$ between shield inner surface and the sensor may result in an error in air temperature measurement of up to $1.4{ }^{\circ} \mathrm{C}$ during the day (Lin et al., 2001a). As an insulative material, the foil bubble wrap has low thermal conductivity $\left(0.035 \mathrm{~W} \cdot \mathrm{m}^{-1}\right.$ ${ }^{\circ} \mathrm{C}^{-1}$ ); therefore, one would expect heat from the external surface of the shield to be conducted poorly to the inner surface of the shield, a desirable attribute for singlewalled shields.

In a study of passively ventilated shields for weather stations, including a commercial Gill shield, solar radiation entering the shields increased linearly as the albedo of the underlying surface increased (Hubbard et al., 2001). Over a highly reflective surface of simulated snow, in the absence of wind, temperature errors in excess of $+5{ }^{\circ} \mathrm{C}$ were reported for air temperatures measured in the Gill shield, $\approx 1.6$ times the error that was recorded for temperatures measured over grass under the same experimental conditions (Gill, 1983). These observations are relevant to horticultural applications where the surface could be a natural or plastic mulch of relatively high albedo. In the present study, shields with open bottoms (tube, pagoda, rocket, cone) tended toward higher daytime $\Delta \mathrm{T}$. A potential disadvantage of a material like the foil bubble wrap used here lies with its optical properties; surfaces exhibiting specular reflectance can allow multiple reflections of solar radiation inside the shield and intense reflected radiation to strike the sensor. One might address such an issue by painting the interior surface of the material flat white.

The daytime energy balance of a shield is dominated by incoming shortwave (i.e., solar) radiation and outgoing convective heat transfer (Lin et al., 2001a). Passively ventilated radiation shields cannot completely block solar radiation without simultaneously impeding air flow, which decouples the sensor from the air that is to be measured and in turn leads to inaccurate estimates of actual air temperature. General guidelines (WMO, 2006) suggest a deviation of the microclimate inside a shield from the surrounding air mass at ambient wind speeds less than $1 \mathrm{~m} \cdot \mathrm{s}^{-1}$. Among passively ventilated shield configurations, vertically oriented tubes provide excellent shielding from direct beam solar radiation at many solar elevation angles (i.e., times of the day) but at a cost of the solid wall compromising convective heat transfer away from the shield and the sensor. With its high potential for ventilation, the stacked plate design does not eliminate errors of this nature but relegates them to lower solar elevation angles where solar radiation also is less intense. In the standard Gill design, solar elevation angle had only a small effect on errors in temperature measurement, 


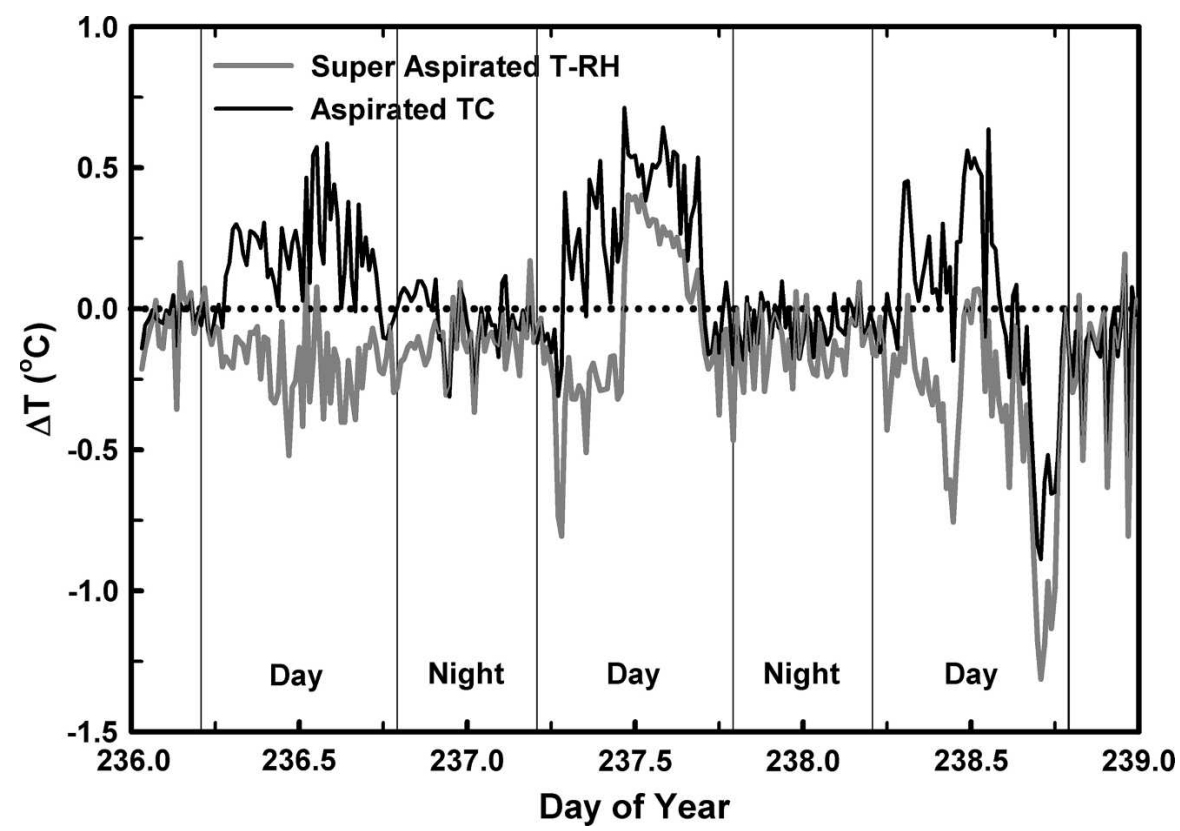

Fig. 8. Difference in measured air temperature $(\Delta \mathrm{T})$ between sensors in aspirated radiation shields and the same type of sensor in a standard commercial Gill shield over three exemplary days with clear skies and maximum global irradiance of 800 to $830 \mathrm{~W} \cdot \mathrm{m}^{-2}$. Vertical lines demarcate day (periods 2 to 6) and night (periods 1,7).

most noticeable at ambient wind speeds below $0.4 \mathrm{~m} \cdot \mathrm{s}^{-1}$; there was little or no effect of solar elevation angle when wind speeds exceeded $1.2 \mathrm{~m} \cdot \mathrm{s}^{-1}$ (Gill, 1983).

Our simplest plate shield, the cone, maximizes ventilation efficiency through its open bottom, but at a cost of substantial error at many solar elevation angles and from radiation that may be reflected from the underlying surface. The pagoda, an open-bottomed shield with a nearly solid sidewall, had a response surface ( $\Delta T$ versus $R_{s}$ and wind) most closely resembling that of the cone, although $\Delta \mathrm{T}$ was driven by a different mechanism. There was no significant effect of wind on the $\Delta \mathrm{T}$ of the pagoda, contrary to the significant effect of wind on $\Delta \mathrm{T}$ in the cone. In the pagoda, a minimally perforated sidewall $(10 \%$ perforation near the top of the tube) obstructed wind, thus reducing the effectiveness of convective heat transfer, whereas in the cone, even low wind speeds allowed forced convection of heat away from the sensor and shield. The pagoda demonstrated both the drawback inherent in vertical tube shields and the drawback of an open or unshielded bottom.

The double cone is the simplest alternative design to address the problem of shielding the sensor from below. Compared with the commercial Gill, midday $\Delta \mathrm{T}$ of the double cone may be higher than is acceptable for many experiments. Midday $\Delta \mathrm{T}$ of the double cone were less than $1^{\circ} \mathrm{C}$ larger than those produced by the handmade Gill shield, which may be acceptable in applications with less stringent accuracy requirements or in plots where the shield is partially shaded in the middle of the day. The handmade Gill costs U.S. \$2.00 more in materials and requires 25 min longer to construct than the double cone. The handmade Gill could not supplant aspirated shields in heat transfer studies, where measurement accuracies of $\pm 0.1{ }^{\circ} \mathrm{C}$ may be required, but for studies of growth and development, where measurement accuracy of $\pm 1{ }^{\circ} \mathrm{C}$ may be sought (e.g., Perrier, 1971), a shield design similar to the handmade Gill described here may offer a cost-effective choice for passively ventilated shielding. Tanner (1990) suggested that it would be unrealistic to expect accuracies better than $\pm 1{ }^{\circ} \mathrm{C}$ for air temperatures measured in naturally ventilated shields under full sunlight and winds below 3 to $4 \mathrm{~m} \cdot \mathrm{s}^{-1}$.

That nighttime air temperatures were not significantly different between the commercial Gill and any experimental shield confirms the generally held understanding that daytime shortwave-driven errors in the measurement of air temperature are most important in field studies. Longwave radiation governs the radiation balance of the shield at night, but nocturnal errors in temperature measurement tend to be smaller than daytime errors. Air temperature in all of the experimental shield designs was lower than that in the commercial Gill at night, predominantly the result of the shields' longwave radiation balance given consistently low wind speeds. Longwave radiation exchange is of secondary importance during the day because it is emitted from sources whose temperatures are similar to that of the temperature sensor itself.

The goal of aspiration is to balance the effect of radiation load on the shield through convection regardless of ambient wind speed so that the shielded sensor remains coupled to ambient air and returns an accurate measurement of air temperature. Errors in the mea- surement of air temperature are inversely proportional to air speed in the shield because energy transfer away from the shield is dominated by convection. Standards for weather stations (e.g., ASAE, 2004) do not specify minimum aspiration rates, but guidelines published for measuring environmental variables in plant growth chambers suggest shielding temperature sensors with a reflective material and aspirating them at $3 \mathrm{~m} \cdot \mathrm{s}^{-1}$ or greater (ASAE, 2002). Mounting a fan atop a Gill shield (Crescenti et al., 1989) resulted in unacceptable errors in measurements of air temperature because the fan battery and mounting assembly self-heated and because the fan drew air across only the top two plates rather than from the bottom to the top. The aspirated TC and superaspirated T-RH shields in the present study, given their similar and frequently lower values of air temperature relative to those in the commercial Gill, indicate sufficient ventilation rates were achieved to offset the radiation loads of those shields. Elsewhere, when wind speed inside a modeled radiation shield was 0.7 $\mathrm{m} \cdot \mathrm{s}^{-1}$, which corresponded to an ambient wind speed of $2.4 \mathrm{~m} \cdot \mathrm{s}^{-1}$, all expected measured air temperatures were within $\pm 0.5{ }^{\circ} \mathrm{C}$ of actual air temperature (Lin et al., 2001a). At very low wind speed $\left(0.5 \mathrm{~m} \cdot \mathrm{s}^{-1}\right)$ and high irradiance (greater than $900 \mathrm{~W} \cdot \mathrm{m}^{-2}$ ), Gill (1979) recorded a temperature error of +1.5 ${ }^{\circ} \mathrm{C}$ in the developmental version of what now has become the commercial Gill shield. Where power is available, sufficiently aspirated radiation shields remain the ideal for field experiments.

\section{Conclusion}

Because any solar shield will impede ventilation, investigators must balance solar shielding with the potential for sufficient convective heat transfer away from the shield and its sensor. A potentially effective radiation shield designed around stacked plates like the commercial Gill shield (U.S. \$180) can be constructed from a readily available, inexpensive, lightweight, and highly reflective material at a cost of U.S. $\$ 4.00$ in materials and 45-min assembly time. Eightyseven percent of all midday measurements of air temperature in this "homemade Gill" were $1.5{ }^{\circ} \mathrm{C}$ or less above those recorded in commercial Gill shields; two-thirds of all observed $\Delta \mathrm{T}$ were $1.0^{\circ} \mathrm{C}$ or less. Regardless of configuration among the in-house passively ventilated shields, the combination of low ambient wind speed (less than $1 \mathrm{~m} \cdot \mathrm{s}^{-1}$ ) and high global irradiance (greater than 600 $\mathrm{W} \cdot \mathrm{m}^{-2}$ ) produced the largest $\Delta \mathrm{T}$, the magnitude of which varied with shield design; stacked plate configurations had lower $\Delta \mathrm{T}$ than tube-based configurations. Nighttime $\Delta \mathrm{T}$ were inconsequential for all shields. Open-bottomed radiation shields are not advised, particularly over reflective surfaces. The smallest daytime $\Delta \mathrm{T}$ were between aspirated shields and the commercial Gill, averaging less than $\pm 0.5{ }^{\circ} \mathrm{C}$. Our results suggest that thermocouples in small aspirated 

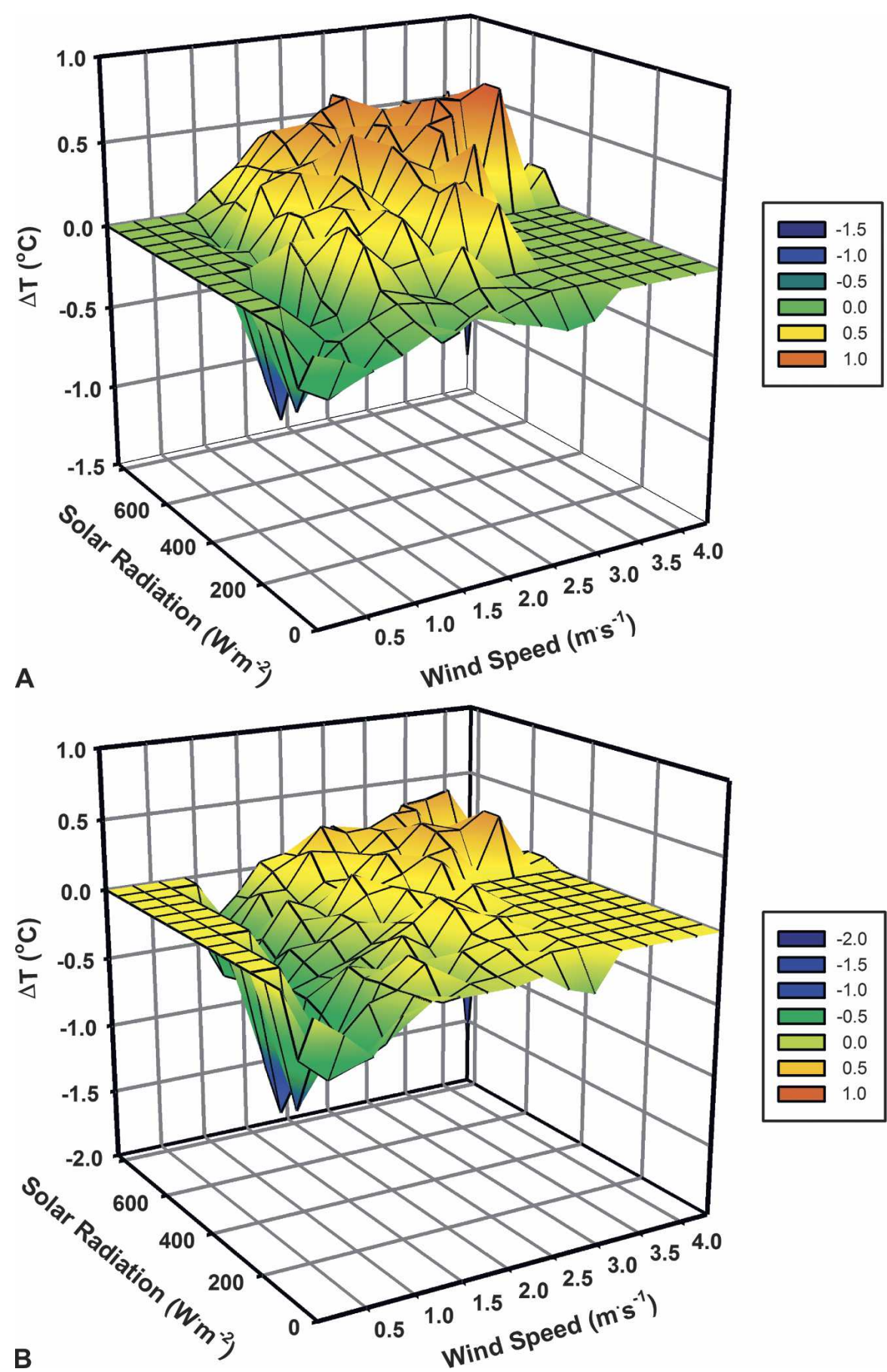

Fig. 9. Response surface of the difference in measured air temperature $(\Delta T)$ between sensors in an experimental radiation shield and the same type of sensor in a standard commercial Gill shield against the two main driving forces of $\Delta \mathrm{T}$, solar radiation [global irradiance $\left(\mathrm{R}_{\mathrm{s}}\right)$ ] and wind speed. (A) Aspirated thermocouple shield (aspirated TC), with constant air flow of $1.8 \mathrm{~m} \cdot \mathrm{s}^{-1}$. (B) Superaspirated temperature-relative humidity shield (superaspirated T-RH) with a constant air flow of $4.4 \mathrm{~m} \cdot \mathrm{s}^{-1}$.

shields may be in equilibrium with ambient air at aspiration rates above $1 \mathrm{~m} \cdot \mathrm{s}^{-1}$, but combined temperature-RH sensors in higher-volume shields require higher aspiration rates (e.g., $4 \mathrm{~m} \cdot \mathrm{s}^{-1}$ ) to minimize diver- ces available for achieving the desired level of replication.

\section{Literature Cited}

ASAE. 2002. Guidelines for measuring and reporting environmental parameters for plant experiments in growth chambers. ASAE EP411.4. American Society of Agricultural Engineers, St. Joseph, MI

ASAE. 2004. Measurement and reporting practices for automatic agricultural weather stations. ASAE Standard EP505. American Society of Agricultural Engineers, St. Joseph, MI

Campbell, G.S. and J.M. Norman. 1998. An introduction to environmental biophysics. Springer, New York.

Crescenti, G.H., R.E. Payne, and R.A. Weller. 1989. Improved meteorological measurements from buoys and ships (IMET): Preliminary comparison of solar radiation air temperature shields. WHOI-89-46. Woods Hole Oceanographic Institute, Woods Hole, MA.

Fritschen, L.J. and L.W. Gay. 1979. Environmental instrumentation. Springer-Verlag, New York.

Fuchs, M. and C.B. Tanner. 1965. Radiation shields for air temperature thermometers. J. Appl. Meteorol. 4:544-547.

Gill, G.C. 1979. Development of a small rugged radiation shield for air temperature measurements on drifting buoys. Report to NOAA Data Buoy Office for Development Contract \#01-7038-827 (IF). Bay, St. Louis, MO.

Gill, G.C. 1983. Comparison testing of selected naturally ventilated solar radiation shields. Report to NOAA Data Buoy Office for Development Contract \#NA-82-0A-A-266. Bay, St. Louis, MO.

Hubbard, K.G., X. Lin, and E.A. Walter-Shea 2001. The effectiveness of the ASOS, MMTS, Gill, and CRS air temperature radiation shields. J. Atmos. Oceanic Technol. 18:851864.

Lin, X., K.G. Hubbard, and E.A. Walter-Shea 2001a. Radiation loading model for evaluating air temperature errors with a nonaspirated radiation shield. Trans. ASAE 44: 1299-1306.

Lin, X., K.G. Hubbard, E.A. Walter-Shea, and J.R. Brandle. 2001b. Some perspectives on recent in situ air temperature observations: Modelling the microclimate inside the radiation shields. J. Atmos. Oceanic Technol. 18:1470-1484

Monteith, J.L. and M.H. Unsworth. 1990. Principles of environmental physics. Edward Arnold, London.

Perrier, A. 1971. Leaf temperature measurement, p. 632-671. In: Z. Sestak, J. Catsky, and P.G. Jarvis (eds.). Plant photosynthetic production Manual of methods. W. Junk, The Hague.

Tanner, B.D. 1990. Automated weather stations. Remote Sensing Reviews. 5:73-98.

Wheeler, E.F., J.L. Zajaczkowski, and R.E. Graves. 2002. Effect of solar shielding on portable datalogger temperature readings. Trans. ASAE 19:473-481.

WMO. 2006. Guide to meteorological instruments and methods of observation. WMO-No.8. World Meteorological Organization, Geneva. 